\title{
Life Cycle Risks for Human Health: A Comparison of Petroleum Versus Bio-Based Production of Five Bulk Organic Chemicals
}

\author{
Alexander L. Roes, MSc ${ }^{1 *}$ and Martin K. Patel ${ }^{1}$
}

\begin{abstract}
This article describes the development and application of a generic approach to the comparative assessment of risks related to the production of organic chemicals by petrochemical processes versus white biotechnology. White biotechnology, also referred to as industrial biotechnology, typically uses bio-based feedstocks instead of the fossil raw materials used in the petrochemical sector. The purpose of this study was to investigate whether the production of chemicals by means of white biotechnology has lower conventional risks than their production by petrochemical processes. Conventional risks are the risks of well-established processes, and not those related to genetically modified microorganisms and plants. Our approach combines classical risk assessment methods (largely based on toxicology), as developed by the life cycle assessment (LCA) community, with statistics on technological disasters, accidents, and work-related illnesses. Moreover, it covers the total process chain for both petrochemical and bio-based products from cradle to grave. The approach was applied to five products: the plastics polytrimethylene terephthalate (PTT), polyhydroxyalkanoates (PHA), polyethylene terephthalate (PET), polyethylene (PE), and ethanol. Our results show that the conventional risks related to the white biotechnology products studied are lower than those of the petrochemical products. However, considering the uncertainties with respect to the ranges of input data, the (incomplete) coverage of emissions by the environmental priority strategies (EPS) 2000 method, and the uncertainties of the assumptions made in this study (i.e., large to very large), the differences in results between bio-based and petrochemical products fall into the uncertainty range. Because of this, future research is necessary to decrease the uncertainties before we can conclude that the conventional risks of biotechnologically produced chemicals are lower than those of fossil-fuel-derived chemicals.
\end{abstract}

KEY WORDS: Bio-based chemicals; conventional risks; industrial biotechnology; life cycle risks; white biotechnology

\section{INTRODUCTION}

Enormous progress has been made in biotechnology (including genetic engineering) in the past few years and more major scientific and technolog-

\footnotetext{
${ }^{1}$ Utrecht University, Copernicus Institute, Department of Science Technology and Society (STS), Heidelberglaan 2, 3584 CS Utrecht, The Netherlands.

* Address correspondence to A. L. Roes, Utrecht University; tel: +3130 2537615; a.l.roes@uu.nl.
}

ical breakthroughs are expected in the near future. In addition to the recent advances in food and animalfeed production ("green biotechnology") and medical applications ("red biotechnology"), biotechnology is about to open new perspectives for the manufacture of organic chemicals and their intermediates. This type of technology is referred to as "white biotechnology" or "industrial biotechnology." There are high expectations for white biotenology with regard to its usefulness for science, technology, and society in the 
medium to long term. Because of the (expected) risks, there is broad public resistance to green biotechnology in many European countries. Red biotechnology, however, is widely accepted. It is as yet unknown how the general public will react to white biotenology.

In the present study, we developed and applied a generic approach to the risk assessment of the production of petrochemicals and white biotenology chemicals made from renewable resources (bio-based). We limited ourselves to conventional risks, that is, risks of well-established processes to human health and life, taking into account accidents, illnesses, and external risks imposed on the public by emissions and technological disasters. Risks caused by genetically modified microorganisms (GMO) and plants, which are probably more decisive for public acceptance, were excluded. These nonconventional risks were investigated in the BREW study. ${ }^{(2)}$

This article discusses the conventional risks of producing five organic products, namely, polytrimethylene terephthalate (PTT), polyhydroxyalkanoates (PHA), polyethylene terephthalate (PET), polyethylene (PE), and ethanol. Moreover, it compares the risks related to bio-based chemical production with those of conventional petrochemical production. Our approach combines the classical risk assessment methods developed by the life cycle assessment (LCA) community with statistics on technological disasters, accidents, and work-related illnesses. It was not obvious beforehand what the outcome would be because the agricultural sector (which provides the raw materials for white biotenology) is known for its high accident rate, while the manufacture of white biotenology chemicals has lower requirements for fossil feedstocks and process energy and thus lower related risks. In order to assess the total risks, the new method had to cover the total process chain for both petrochemical and bio-based products from cradle to grave.

\section{METHODOLOGY}

This section explains the methodology that was used for the comparative risk assessment of bio-based chemicals and petrochemical products. The method is generic in the sense that it is based on risk relationships that are representative of the various steps in the process chain. In other words, it allows one to make a first estimate of the conventional risks in the total system leading to a given chemical. The process chain encompasses the entire life cycle of a chemical from "cradle" to "grave" and thus includes the fol- lowing six sectors: agriculture, extraction and refining of fossil fuels, chemical industry, power generation, transport, and waste management.

Due to incomplete information, we could not consider the risks to the environment. As a result, we limited our analysis to human health risks. The total risk to human health throughout a chemical's life cycle was estimated by summing the results of the following four risk categories:

- External risks (risks imposed on the public) due to the release of emissions from regular operation;

- External risks due to technological disasters;

- Risks of work-related accidents; and

- Risks of work-related illnesses.

Risk assessment was conducted as follows: for each of the four risk categories listed above, we first estimated the total risk for each of the six sectors involved (agriculture, extraction, etc.) for Western Europe as a whole. We then divided these totals by suitable reference flows (see below and second column of Table II). This resulted in specific risk indicators for each sector. Since specific risk indicators could be distinguished for the various types of risks, the values for each sector could be presented in the form of a matrix. The energy, material, and transport requirements in the life cycles of our products (energy and material, data taken from Reference 2) can each be categorized into one of the sectors of the matrix and their unit can be expressed according to the reference flow of that sector. Multiplication of the life cycle input data (in TJ or tkm) by the risks of the respective reference flows of the given process chain (system) and summation of the intermediate offered a way to generically assess the overall risk. The next section explains the development of the risk matrix for each of the four categories.

\subsection{External Risks Due to Regular Release of Emissions}

We based the quantification of the risks to human health on the Environmental Priority Strategies (EPS) 2000 method, ${ }^{(3)}$ which is a "single-score method." "Single score" means that the various impact categories (e.g., human toxicity, climate change, acidification, etc.) are aggregated into one single indicator by means of weighting factors. The outcome is a single value for a given case. Using the EPS 2000 method, the number of "personyears" lost is the common indicator chosen to measure the impact on hu- 
Table I. Categories of Impact on Human Health and Their Weighting Factors According to the EPS 2000 Method

\begin{tabular}{lcc}
\hline $\begin{array}{l}\text { Human Health } \\
\text { Impact }\end{array}$ & $\begin{array}{c}\text { Weighting Factor } \\
\text { Environmental Load } \\
\text { Units } / \text { /Personyear) }\end{array}$ & $\begin{array}{c}\text { Weighting Factor } \\
\text { Normalized to } \\
\text { "Life Expectancy" }\end{array}$ \\
\hline Life expectancy & 85,000 & 1 \\
Severe morbidity & 100,000 & 1.1765 \\
Morbidity & 10,000 & 0.11765 \\
Severe nuisance & 10,000 & 0.11765 \\
Nuisance & 100 & 0.0011765 \\
\hline
\end{tabular}

a "Environmental load units" were used in the EPS method to express final environmental impacts.

man health. EPS methodology incorporates estimates of the hazard (damage potential) and the probability of its occurrence and is, therefore, a suitable method to express risk to human health. It distinguishes the following five categories of impact on human health:

- Life expectancy: defined as years of life lost (YOLL);

- Severe morbidity and suffering: defined as the time a human suffers severe morbidity, including starvation;

- Morbidity: defined as the time a person suffers morbidity like a cold or the flu;

- Severe nuisance: defined as a nuisance that would normally cause an evasive reaction;

- Nuisance: defined as something that is irritating, but does not cause any direct action.

The categories are all weighted differently, as can be seen in Table I. Weighting factors reflect "willingness to pay" to avoid the impact imposed on human health. By dividing each weighting factor by the weighting factor of the category "life expectancy," we were able to express all of the categories in terms of personyears of "life expectancy" (YOLL). This unit was used to quantify the risks of all inputs in this risk assessment.

The risks according to EPS 2000 were calculated for each sector using the LCA tool Simapro $6 .^{(4)}$

For the agriculture sector, 1 ton of maize was chosen as the reference flow because grain-derived glucose is the substance most likely used in Europe in the production of chemicals by means of white biotenology. ${ }^{1}$ The risks related to the use of 1 ton of maize, expressed in YOLL, were calculated with SimaPro 6

\footnotetext{
1 In tropical regions, sucrose from sugar cane and vegetable oils are more likely to be the feedstocks of choice. If the technology can be successfully developed, fermentable sugar feedstocks will also be made available from lignocellulosic feedstocks, such as wood.
}

using data from Reference 5). The outcome was then divided by the calorific value of the crop $(14.9 \mathrm{GJ} / \mathrm{ton}$; see the second column in Table II).

The total emissions of the "mineral oil and gas refineries" in EU-15(6) were used for the extraction and refining of fossil fuels sector. We used these emissions to conduct impact assessments according to EPS 2000 with the help of SimaPro 6. The results of the human health risks were divided by the total crude oil consumption of the petroleum refineries in the EU in 2000 (ca. 28,200 PJ according to Reference $7^{2}$ ). The same approach was chosen for the chemical industry sector: total emissions from the production of "basic organic chemicals" in EU-15 countries were taken from Brand et al. ${ }^{(6)}$ The result calculated with SimaPro 6 was then divided by the total petroleum product feedstock consumption of the chemical and petrochemical industry in the EU in 2000 (ca. 2,700 $\mathrm{PJ}$ according to Reference 7$)^{3}$. For the power generation sector, we calculated the impact of $1 \mathrm{TJ}$ of electricity using SimaPro 6 (weighted electricity mix of the UCTE, CENTREL, and NORDEL grid). ${ }^{4} \mathrm{We}$ also assumed that all transport took place with a 32ton load-capacity lorry. Data were from Spielmann et $a l .{ }^{(8)}$. Finally, the impact of the incineration of $1 \mathrm{TJ}$ of polyethylene terephtalate (PET) $(\mathrm{HHV}=23.13$ $\mathrm{GJ} /$ ton) was used for the waste management sector (SimaPro, using data from Reference 9). We assumed that this incineration process could be applied equally to the three other plastics (PTT, PHA, and PE) and to ethanol (for convenience, the method was applied to ethanol even though direct combustion of ethanol or its derivatives in a waste incineration plant is very unlikely due to the predominant use of ethanol as transportation fuel). Electricity and heat are produced during the incineration of PET. ${ }^{5}$ To account for the avoidance of the conventional production of electricity and

2 This value is also used to express risks due to accidents and illnesses in the next paragraphs.

3 This value is also used to express risks due to accidents and illnesses in the next paragraphs.

4 The categories chosen in Simapro are

- Electricity, medium voltage, production UCTE, at grid/ UCTE S

- Electricity, medium voltage, production CENTREL, at grid/ CENTREL S

- Electricity, medium voltage, production NORDEL, at grid/ NORDEL S

The three categories were weighted according to their production shares, namely, 74\% UCTE, 11\% CENTREL, and 15\% NORDEL. ${ }^{(16)}$

5 During the incineration of $1 \mathrm{TJ}$ PET, $0.106 \mathrm{TJ}$ of electricity and $0.217 \mathrm{TJ}$ of heat were obtained. It was assumed that the heat was obtained in the form of steam. The risks are valued negatively, 
Table II. Risk Indicator Matrix in "Years of Life Lost" (YOLL) Expressed per Reference Unit

\begin{tabular}{|c|c|c|c|c|c|c|c|}
\hline $\begin{array}{l}\text { All } \\
\text { Values } \\
\text { in YOLL }\end{array}$ & $\begin{array}{l}\text { Reference } \\
\text { Unit }\end{array}$ & $\begin{array}{c}\text { Fatal } \\
\text { Accidents }\end{array}$ & $\begin{array}{c}\text { Accidents }> \\
3 \text { Days } \\
\text { Absence }\end{array}$ & $\begin{array}{c}\text { Musculoskeletal } \\
\text { Health } \\
\text { Problems }\end{array}$ & $\begin{array}{l}\text { Pulmonary } \\
\text { Health } \\
\text { Problems }\end{array}$ & $\begin{array}{c}\text { EU } \\
\text { Emissions }\end{array}$ & Total \\
\hline Agriculture & $1 \mathrm{TJ}$ crop output & $5.11 \mathrm{E}-3$ & $1.06 \mathrm{E}-3$ & $1.48 \mathrm{E}-4$ & $5.01 \mathrm{E}-3$ & -0.0321 & -0.0208 \\
\hline $\begin{array}{l}\text { Extraction and refining } \\
\text { of fossil fuels }\end{array}$ & $1 \mathrm{TJ}$ crude oil consumption & $8.18 \mathrm{E}-6$ & $7.08 \mathrm{E}-7$ & $6.88 \mathrm{E}-7$ & $2.47 \mathrm{E}-5$ & 0.00716 & 0.00719 \\
\hline Chemical industry & $1 \mathrm{TJ}$ fossil feedstock consumption & $5.72 \mathrm{E}-4$ & $2.18 \mathrm{E}-4$ & $8.49 \mathrm{E}-5$ & 0.003 & 0.0372 & 0.0411 \\
\hline Power generation & 1 TJ electricity output & $1.26 \mathrm{E}-4$ & $1.86 \mathrm{E}-5$ & $9.19 \mathrm{E}-6$ & $3.2 \mathrm{E}-4$ & 0.245 & 0.245 \\
\hline Transport & $1 \mathrm{tkm}$ road and rail freight transport & $1.11 \mathrm{E}-8$ & 2.7E-9 & $2.89 \mathrm{E}-10$ & $4.46 \mathrm{E}-9$ & $3.48 \mathrm{E}-7$ & 3.67E-7 \\
\hline Waste management & $1 \mathrm{TJ}$ incinerated waste & - & - & - & - & 0.0517 & 0.0517 \\
\hline
\end{tabular}

heat (in the form of steam), their respective impacts (risks) were subtracted from the other risks.

\subsection{External Risks Due to Technological Disasters}

Technological disasters with fatalities appear to be relatively rare occurrences. ${ }^{(10)}$ In conventional databases on disasters, no distinction is made between fatalities among employees on the production site ("onsite") and citizens outside the production site where the disaster took place. ${ }^{(11)}$ As a result, it is difficult to quantify external risks due to technological disasters. References 10,12, and 13 report statistics on technological disasters. Based on these data, we estimated the total number of fatalities outside the production site (external fatalities) to be between 1 and 20 per year in Western Europe. As will be discussed below, this is very few compared to the impacts of the other categories.

\subsection{Accidents}

We included two types of accidents in our risk assessment: fatal accidents and accidents causing more than 3 days of absence from work. Several assumptions needed to be made in order to convert data on the occurrence of such accidents (data for 1999 from Reference 14) into YOLL. Since these assumptions are subject to substantial uncertainty, an uncertainty analysis has been included in Section 4.

however, since electricity and heat are produced instead of used. The risk from electricity production was calculated using Simapro similar to what was done in the section "power generation" and risk from steam using data from Reference 17.

\subsubsection{Fatal Accidents}

It is necessary to estimate the number of years of life that are lost in fatal accidents. This is done by assuming the average age of the individuals who died in a fatal accident and deducting this value from the average life expectancy. ${ }^{6}$ We found that one fatal accident was equivalent to 35 YOLL.

\subsubsection{Accidents $>$ Three Days Absence}

For accidents resulting in more than 3 days of absence from work, we first assumed that the EPS category "morbidity" was equivalent to 0.11765 YOLL (see Table I). We then estimated the average period of absence from work using another data source ${ }^{(15)}$ and arrived at 30 lost working days per accident with more than 3 days of absence. ${ }^{7}$ Finally, we concluded

6 The following assumptions/estimates were made:

- We assumed (1) that workers are employed from the age of 20 to 65 years and (2) that there is a uniform probability of a fatal accident during this period. The average age at which a fatal accident occurs then was estimated to be 42.5 .

- Life expectancy for EU-15 in 2002 was 75.8 years for males and 81.6 years for females. ${ }^{(18)}$

- The majority of the workers in industry is male. According to, Reference $19,75 \%$ of the workers in manufacturing are male. This results in the average life expectancy in manufacturing to be $(0.75 \times 75.8+0.25 \times 81.6=) 77.25$ years.

- A fatal accident thus reduces, on an average, a life period from 77.25 years to 42.5 years. This means 34.75 years of life lost (YOLL).

7 According to Reference 15, every year nearly 5 million employees in the EU suffer from work-related accidents involving more than 3 days' absence from work and a further 5,500 are killed. In other words, 150 million workdays are lost. Due to the lack of more detailed data, we made the simplifying assumption that all workdays are lost due to accidents involving more than 3 days' absence from work. One accident involving one employee, therefore, causes 30 lost working days ( = 150 million/5 million). 
that one accident of this type was equivalent to 0.0136 YOLL. ${ }^{8}$

Data on the occurrence of accidents are available for five of the six sectors ${ }^{9}$ included in our risk analysis (data from Reference 14). Specific risk indicators were estimated by division by the activity level in the respective sector. ${ }^{10}$

\subsection{Work-Related Illnesses}

Two types of work-related illnesses (reported by Reference 14) were considered to be most relevant for this risk assessment: pulmonary health problems and musculoskeletal health problems. ${ }^{11}$ Data on the prevalence of these health problems were converted to YOLL, as discussed below.

\subsubsection{Pulmonary Health Problems}

We assumed pulmonary health problems to fall under the category "morbidity" (see Table I). Some occupational respiratory diseases take several decades to develop (e.g., respiratory cancer, asbestosis, and silicosis) and quite often become apparent only after retirement. ${ }^{(14)}$ It was assumed, therefore, that the period of suffering from a pulmonary health problem is only 10 years. As a result, we achieved a value of 1.1765 YOLL per pulmonary health problem.

\subsubsection{Musculoskeletal Health Problems}

Like pulmonary health problems, we considered musculoskeletal health problems to also fall under the category "morbidity." Using additional data from the

8 With 260 working days in a year, one accident causes 30/260 = 0.115 years of morbidity. Multiplication with a weighting factor of 0.11765 according to Table I gives a value of 0.0136 YOLL.

9 Data on accidents are not available for waste management.

10 The following data were used as a proxy for the activity level in the various sectors:

- For agriculture, the total crop production in the EU-15 countries amounted to 4,520 TJ in 1999. ${ }^{(20)}$

- For extraction and refining of fossil fuels, see text on external risks.

- For chemical industry, see text on external risks.

-For power generation, the total amount of electricity generated by electricity plants and CHP plants in EU-15 countries in the year 2000 was used as reference (9,200 PJ according to Reference 7.

- For transport, road freight transport $(1,320 \mathrm{Gtkm})$, and rail freight transport (240 Gtkm) add up to $1,560 \mathrm{Gtkm}$.

- For waste management, only emission data already expressed per TJ waste were available.

11 We did not take into consideration the category "Stress, depression, or anxiety."(14)
United Kingdom, we were able to estimate that one case of muscoskeletal health problems represented 0.004525 YOLL. ${ }^{12}$

\subsection{Risk Indicator Matrix}

The combination of the data discussed above led to the risk indicator matrix shown in Table II, and forms the basis for the risk assessment in this study. In some cases, different sources from different years provided different data on accidents and thus resulted in a data range. Table II presents only average values.

\section{RESULTS}

Applying the risk assessment method described above to the chosen cases resulted in estimates for the total number of years lost per unit of product throughout the process chain. The final results are shown in Table III for PTT, PHA, PET, PE, and ethanol. Since both petrochemical and bio-based production routes exist for PTT and ethanol, we were able to compare the risks between bio-based and petrochemically derived products. PHA is only produced with bio-based feedstocks, while PET and PE are petrochemical alternatives. Therefore, we compared (biobased) PHA to (petrochemical) PET and PE. The results are shown graphically in Figs. 1-6, distinguishing between the types of risks and the sectors in which the risks occur.

According to the results shown in Figs. 1-6, the conventional risks of all bio-based products are lower than those of the petrochemical products. For example, the total risk of bio-based PTT is $12-25 \%$ lower than that of petrochemical PTT. The risk caused by the production of PHA by fermentation is $7-22 \%$ lower than that caused by the production of petrochemical PET and 39-49\% lower than that of petrochemical PE. The risk caused by the production of ethanol by dry milling is $68-74 \%$ lower than its production from ethene (identical with ethylene). While these results seem to justify the conclusion that the risks related to bio-based products are lower than those for petrochemical products, the uncertainties of the

12 According to Reference 21, there are 1.2 million work-related musculoskeletal health problems in the United Kingdom. According to Reference 22, 12.3 million working days are lost in the United Kingdom due to musculoskeletal health problems. This means that one musculoskeletal health problem causes, on an average, 10 working days of absence. There are 260 working days in a year, which means that one musculoskeletal health problem is 0.0384 personyear of "morbidity." Multiplication with the conversion factor in Table I gives 0.004525 YOLL. 
Table III. Results of the Risk Assessment for PTT, PHA, PET, $\mathrm{PE}$, and Ethanol

\begin{tabular}{lc}
\hline Product & $\begin{array}{l}\text { Risk (YOLL/ } \\
\text { Ton Product) }\end{array}$ \\
\hline $\boldsymbol{P T T}^{\mathrm{a}}$ & \\
-From ethylene oxide & 0.003821 \\
-From acrolein & 0.004031 \\
-Via anaerobic fermentation on dextrose & 0.003001 \\
-Via anaerobic fermentation on glycerol & 0.003227 \\
-Via aerobic fermentation 1 & 0.003039 \\
-Via aerobic fermentation 2 & 0.003381 \\
$\boldsymbol{P H A}^{\text {b }}$ & \\
-Via fermentation 1 & 0.002501 \\
-Via fermentation 2 & 0.002988 \\
$\boldsymbol{P E T}^{\mathrm{c}}$ & 0.003211 \\
$\boldsymbol{P E}^{\text {Ethanol }}$ & 0.004949 \\
-From ethene & \\
-Via maize dry milling 1 (low estimate) & 0.003535 \\
-Via maize dry milling 2 (high estimate) & 0.000934 \\
\hline
\end{tabular}

${ }^{\text {a }}$ PTT from ethylene oxide and acrolein is derived petrochemically. PTT via fermentation is bio-based. Two data sets were available for the aerobic fermentation process. They are called Aer 1 and Aer 2 in Figs. 1 and 2.

${ }^{b} \mathrm{PHA}$ is derived only via fermentation. This is bio-based. Two data sets were available for the fermentation process. They are called PHA 1 (from glucose) and PHA 2 (from glycerol) in Figs. 3 and 4.

${ }^{\mathrm{c}} \mathrm{PET}$ and PE are derived petrochemically.

${ }^{\mathrm{d}}$ Ethanol from ethene is derived petrochemically. Ethanol via maize dry milling is bio-based. Two data sets were available for the dry milling process. They are called dry milling 1 and dry milling 2 in Figs. 5 and 6.

method must be taken into account before drawing final conclusions. An uncertainty analysis, therefore, is presented in Section 4.

As Figs. 1 and 3 show, by far the most important types of risks (expressed as YOLL) are the external risks due to the regular release of emissions to the atmosphere, followed by pulmonary health problems of the workforce and accidents of the workforce (fatal accidents and accidents resulting in more than 3 days of absence). External risks imposed on the public due to technological disasters are negligible.

The results allowed us to compare the distributions of the risks over the risk categories and the industrial activities. We were able to draw the following conclusions. (1) The largest difference between biobased and petrochemical products concerns the risks related to the regular release of emissions to the atmosphere. (2) Pulmonary health problems and fatal accidents tend to be more important in the production of bio-based polymers than petrochemical products, but these differences are by far outweighed by the risks caused by the regular release of emissions to the atmosphere. (3) The breakdown of the total risk by sector shows that the chemical industry is more important for the petrochemical products than for biobased products. (4) Waste management is equal or very similar for all production routes (petrochemical and bio-based) because it is based on the calorific value of the product (the production method had no influence). (5) Transport is equal for bio-based and petrochemical production because the same transport was assumed for all production routes $(500 \mathrm{ton} / \mathrm{km}$ by 32-ton load-capacity lorry). (6) The agriculture sector is only relevant for bio-based production routes. The cultivation of crops yielded a "negative risk" in the agriculture sector because of the uptake by crops of $\mathrm{CO}_{2}$ from the air $\left(\mathrm{CO}_{2}\right.$ uptake is valued as a negative impact by the EPS 2000 method). (7) The share of the extraction and refining of fossil fuels sector tends to be slightly higher for petrochemical production routes. (8) The power generation sector has a similar share in

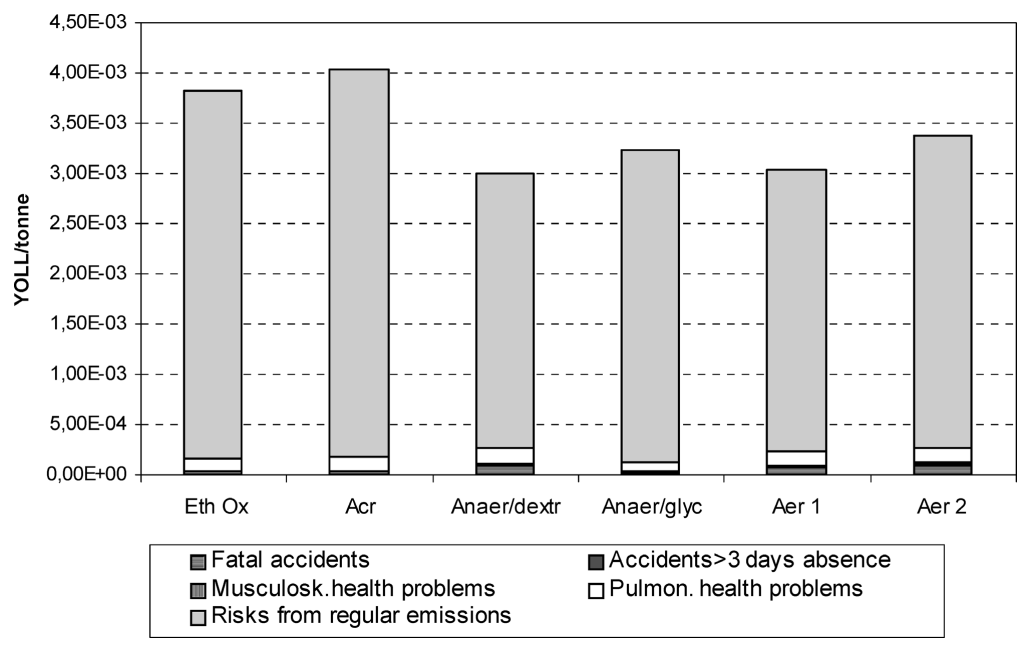

Fig. 1. Risk for 1 ton of polytrimethylene terephthalate (PTT) per risk category (abbreviations: compare Table III). 


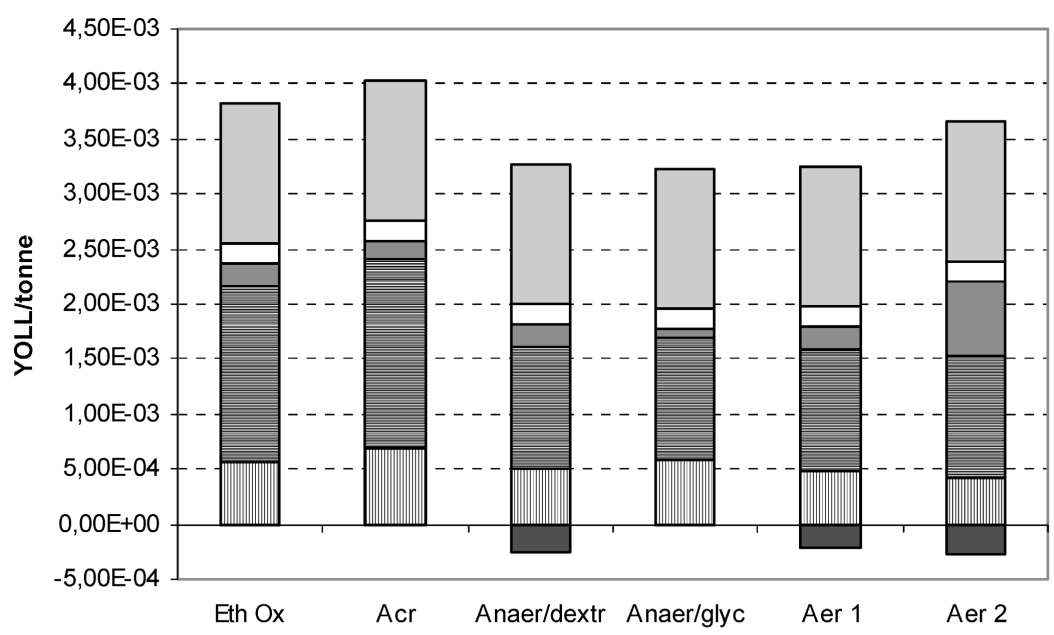

Fig. 2. Risk for 1 ton of PTT per sector.

\begin{tabular}{|ll|}
\hline$\square$ Agriculture & $\square$ Extraction and refining of fossil fuels \\
貝 Chemical industry & $\square$ Power generation \\
$\square$ Transport & $\square$ Waste management \\
\hline
\end{tabular}

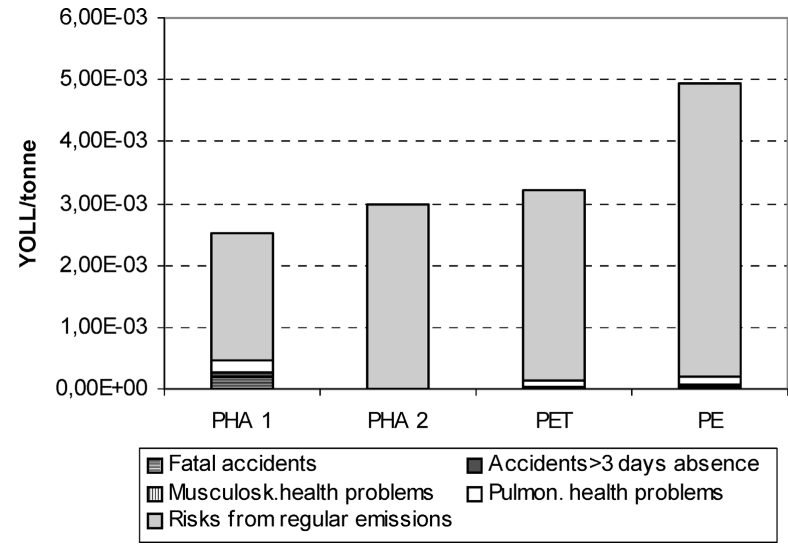

Fig. 3. Risk for 1 ton of polyhydroxyalkanoaates (PHA), polyethylene terephthalate (PET), and polyethylene (PE) per risk category.

both the bio-based and petrochemical production of PTT. Compared to PET and PE, the share is higher for the production of PHA. With regard to the production of ethanol, the share of the power generation sector is very small to negligible in all cases.

\section{UNCERTAINTIES}

In order to assess the quality of our results, we conducted an uncertainty analysis comprising the following factors:

- Ranges of input data (only for accidents; no range was found for the other risk categories);

- Uncertainty analysis for accidents and illnesses;

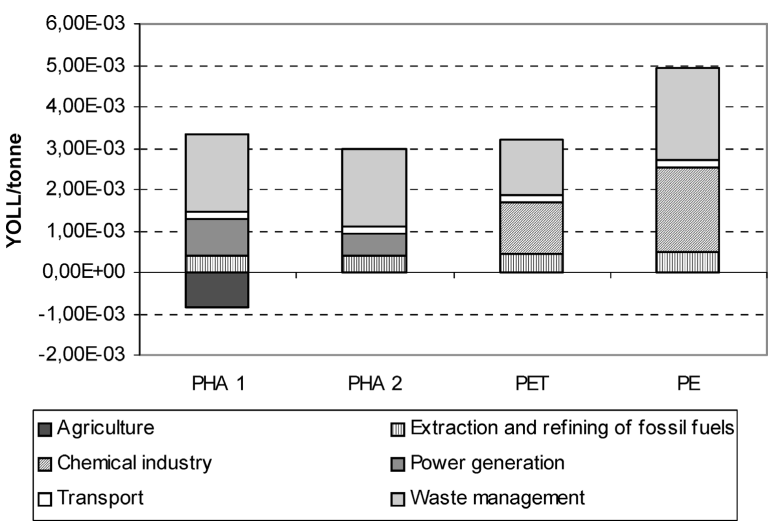

Fig. 4. Risk for 1 ton of PHA, PET, and PE per sector. Note: PHA 1 is produced from glucose, while PHA 2 is produced from glycerol, which is considered a "waste product" (from biodiesel production). For this reason, none of the impacts related to agriculture were allocated to glycerol.

- Coverage of emissions in the SimaPro impact assessment (not all emissions are defined by the EPS 2000 method); and

- Checking the plausibility of the results by comparing them with values taken from other literature sources

\subsection{Ranges of Input Data}

The data sources reported different values for accidents. The ranges are shown in Table IV; the uncertainties ranged from $0 \%$ to $44 \%$. 


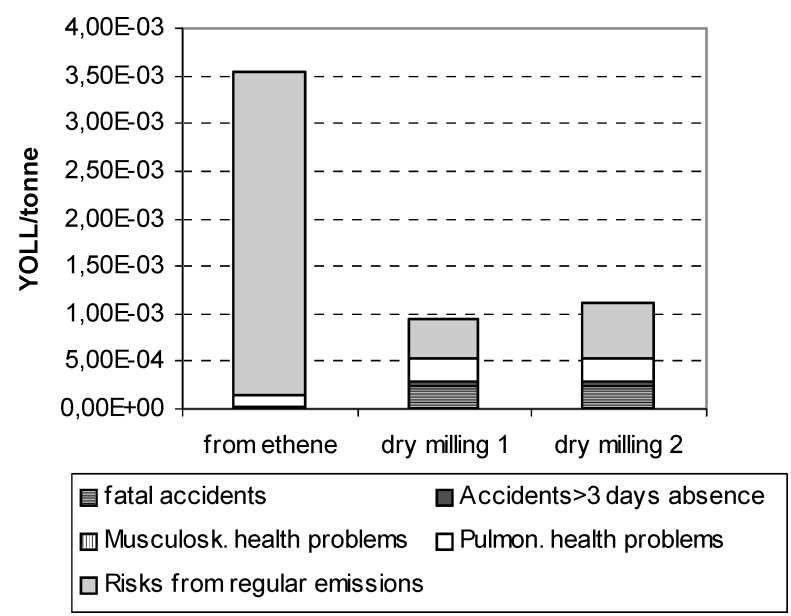

Fig. 5. Risk for 1 ton of ethanol per risk category.

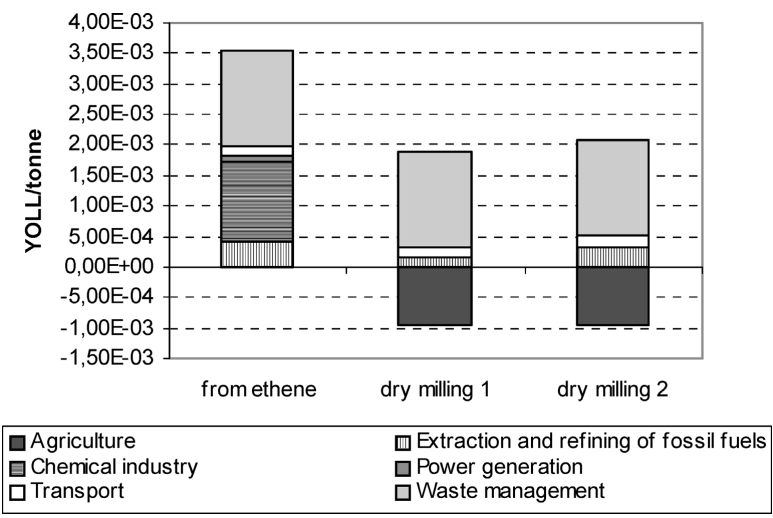

Fig. 6. Risk for 1 ton of ethanol per sector.

\subsection{Uncertainty Analysis for Accidents and Illnesses}

The conversion of accidents and health problems to YOLL is based on assumptions concerning the time period in which a person suffers. This time period can be crucial for the results.

- As explained above (Section 2.3), a fatal accident is assumed to reduce a life, on average, by 35 years. We estimated the uncertainty of this assumption to be \pm 10 years. When the risk due to fatal accidents (see Table II) was recalculated using this \pm 10 -year range, the uncertainty range of this type of risk is $\pm 29 \%$.

- The average period of absence for accidents causing $>3$ days of absence from work was considered to be 30 days. When an uncertainty of \pm 10 days is assumed, the uncertainty for this type of risk is $\pm 33 \%$.
- The assumptions for pulmonary health problems are very rough. We assumed a maximum of 10 years of suffering morbidity. When this period is shortened by 5 years or extended to 35 years (the assumed number of years lost due to a fatal accident), the range of uncertainty becomes roughly $-50 \%$ to $+150 \%$.

- A 10-day absence was assumed for each musculoskeletal health problem. When an uncertainty of \pm 5 days is assumed, the risk uncertainty becomes $\pm 50 \%$.

We found that the contribution of the emissions of "ethanol-dry milling 1 " to the total risk is the lowest compared to the other cases tested. The contribution of the other risk categories is therefore highest. When the uncertainties listed above were applied, an overall maximum uncertainty of the assumptions was obtained (for the other cases-PTT, PHA, PET, PE, and ethanol-dry milling 2-the contributions of accidents and illnesses to the final result are lower, thus the overall uncertainty of the final risk due to the assumptions is also lower than for ethanol-dry milling 1). Recalculation of the final risk using the uncertainty ranges identified above resulted in a lower risk value of $0.000730 \mathrm{YOLL} /$ ton and an upper risk value of $0.001369 \mathrm{YOLL} / \mathrm{ton}$ (original value was 0.000934 YOLL/ton). This means that the maximum uncertainty of the results for all cases is $-22 \%$ and $+47 \%$. In conclusion, the uncertainty range for accidents and illnesses is rather limited and the final result for total risk remains within the same order of magnitude (only for ethanol does the risk pattern change somewhat; emissions remain the dominant risk source for all other cases).

\subsection{Coverage of Emissions by EPS 2000}

The emissions impact for each of the six sectors in this risk assessment was determined using the EPS 2000 method in SimaPro 6. Relatively few types of emissions, however, could be defined using this method (11-32\%; see Table V) and no impact results were calculated for the other types. As a result, the impact determined using the EPS method represents an underestimation of the real impact.

\subsection{Plausibility Check by Comparison with Other Literature Data}

In order to assess whether our results for PTT, PHA, PET, and PE are plausible, we compared our 
Table IV. Data Ranges for Fatal Accidents and Accidents with $>3$ Days of Absence

\begin{tabular}{|c|c|c|c|c|}
\hline & $\begin{array}{c}\text { Fatal } \\
\text { Accidents }\end{array}$ & $\begin{array}{l}\text { Range } \\
\text { (Around } \\
\text { Arithmetic } \\
\text { Mean } \\
\text { Value) }\end{array}$ & $\begin{array}{l}\text { Accidents } \\
\text { > } 3 \text { Days } \\
\text { Absence }\end{array}$ & $\begin{array}{c}\text { Range } \\
\text { (Around } \\
\text { Arithmetic } \\
\text { Mean Value) }\end{array}$ \\
\hline Agriculture & $1.47 \mathrm{E}-4 / \mathrm{TJ}$ & $\pm 3 \%$ & $0.0777 / \mathrm{TJ}$ & $\pm 3 \%$ \\
\hline $\begin{array}{l}\text { Extraction and refining } \\
\text { of fossil fuels }\end{array}$ & 2.36E-7/TJ & $\pm 25 \%$ & No range & $\pm 0 \%$ \\
\hline Chemical industry & $1.65 \mathrm{E}-5 / \mathrm{TJ}$ & $\pm 28 \%$ & No range & $\pm 0 \%$ \\
\hline Power generation & $3.61 \mathrm{E}-6 / \mathrm{TJ}_{\mathrm{e}}$ & $\pm 1 \%$ & 0.00137 /TJ & $\pm 10 \%$ \\
\hline Transport & $3.19 \mathrm{E}-10 / \mathrm{tkm}$ & $\pm 31 \%$ & $1.99 \mathrm{E}-7 / \mathrm{TJ}$ & $\pm 44 \%$ \\
\hline
\end{tabular}

work with the scarce results found in literature. The method of comparison we used is as follows:

If we make the simplifying assumption that the plastics studied in this article are quite representative of plastics (and their production) in general, then the total risk (expressed in YOLL) can be calculated using the (average) results in Table III. When the total risk (in YOLL) of all industrial sectors is known, the share of the plastics sector can be calculated. To check the plausibility of the outcome, this value is compared to the value of the plastic industry's share of the total primary energy supply (TPES) in Europe.

In Europe, the current average production of plastic per capita is $145 \mathrm{~kg}$ (55 Mton plastic produced annually divided by 380 million inhabitants). A total of $145 \mathrm{~kg}$ plastic per capita can be translated to YOLL using the results of our research. Assuming that all plastics consist of PTT, PHA, PET, or PE, the average risk of $145 \mathrm{~kg}$ plastic per capita is $0.5 \mathrm{YOLL} / 1,000$ persons. The total impact of all emissions of all sectors in Europe in 2001 was estimated by Reference 6 to be $6.24 \mathrm{YOLL} / 1,000$ persons. The share of plastic then is $0.5 / 6.24$, that is, $8 \%$.

Plastics are produced by the chemical industry. The primary energy consumption by the chemical and petrochemical industry can be estimated (149 Mtoe) using energy data published by Reference 7. The TPES in 2000 was 1,460 Mtoe. This means that the primary energy use by the European chemical and petrochemical industry was $10 \%$ of the total TPES. This is consistent with the $8 \%$ derived above.
Table V. Coverage of Emissions by EPS 2000

\begin{tabular}{|c|c|c|}
\hline Sector & Impacts Based On & $\begin{array}{l}\text { Fraction of } \\
\text { Emissions Defined } \\
\text { in EPS } 2000^{\mathrm{a}}\end{array}$ \\
\hline Agriculture & Grain maize IP, at farm & $11 \%$ \\
\hline $\begin{array}{l}\text { Extraction and refining of } \\
\text { fossil fuels }\end{array}$ & $\begin{array}{l}\text { EU-15 emissions "mineral oil and } \\
\text { gas refineries" }\end{array}$ & $32 \%$ \\
\hline Chemical industry & $\begin{array}{l}\text { EU-15 emissions "basic organic } \\
\text { chemicals" }\end{array}$ & $28 \%$ \\
\hline Power generation & $\begin{array}{l}\text { CENTREL/NORDEL/UCTE } \\
\text { medium voltage electricity mix, } \\
\text { at grid }\end{array}$ & $11 \%$ \\
\hline Transport & Transport, lorry $32 \mathrm{t}$ & $11 \%$ \\
\hline Waste management & $\begin{array}{l}\text { Disposal, polyethylene } \\
\text { terephtalate, } 0.2 \% \text { water, to } \\
\text { municipal incineration }\end{array}$ & $11 \%$ \\
\hline
\end{tabular}

a This was calculated as the number of substances defined by EPS 2000 divided by the number of substances for which emissions data were available. It was NOT based on the absolute amounts of emissions. For the agriculture, power generation, transport, and waste management sectors, coverage was 63 out of 552 substances. The coverage was 16 out of 50 substances for the extraction and refining of fossil fuels sector and 16 out of 57 substances for the chemical industry sector. 


\section{CONCLUSIONS}

This article describes the successful development and application of a method of generic risk assessment that covers the total process chain of petrochemical and bio-based products from cradle to grave. It focuses on the conventional risks to human health, taking into account accidents, illnesses, and external risks imposed on the public due to emissions and technological disasters. Risks related to GMO and plants are excluded.

As by far the most important sources of risks (expressed as YOLL), we identified the external risks caused by the regular release of emissions into the atmosphere, followed by pulmonary health problems of the workforce and accidents of the workforce (fatal accidents and accidents causing more than 3 days of absence from work). External risks imposed on the public due to technological disasters were found to be negligible.

Our results showed that the chemical industry sector contributed more to the final risks of petrochemical products than bio-based products and that the agriculture sector was only of relevance to biobased products.

We found that the conventional risks are lower for bio-based products than for petrochemical products. This result is partly driven by the lower energy use in the life cycle of the bio-based products because they are produced from bio-based feedstocks and by the fact that bio-based feedstocks take up carbon from the air. Taking into account the uncertainties with respect to the ranges of input data, the (incomplete) coverage of the emissions by EPS 2000, and the uncertainties of the assumptions made in this study (large to very large), the differences in the results between biobased and petrochemical products (in favor of biobased production), however, fall into the uncertainty range. This means that we cannot conclude without due consideration that conventional risks of biotechnologically produced chemicals are lower than those of chemicals derived from fossil fuels. We can suspect that conventional risks are lower for the bio-based chemicals but further research, especially with better data, will have to be conducted in order to decrease the uncertainties so as to make a firm statement on this issue.

\section{ACKNOWLEDGMENTS}

This study was performed as part of the BREW project and has been funded by the European Com- mission under the GROWTH Programme of DG Research (Project No. G5 MA-CT-2002-00014).

\section{REFERENCES}

1. EuropaBio and European Federation of Biotechnology Section on Applied Biocatalysis (ESAB). (2002). Industrial or White Biotenology; A Driver of Sustainable Growth in Europe.

2. Patel, M., Crank, M., Dornburg, V., Hermann, B., Roes, L., Hüsing, B., Overbeek, van, L., Terragni, F., Recchia, E. (2006). Medium and Long-Term Opportunities and Risks of the Biotechnological Production of Bulk Chemicals from Renewable Resources-The BREW Project. Prepared under the European Commission's GROWTH Programme (DG Research). Project team: Utrecht University (UU), Dept. of Science, Technology and Society (STS), Utrecht, Netherlands; Fraunhofer Institute for Systems and Innovation Research (FhG-ISI), Karlsruhe, Germany; Universidad Complutense de Madrid (UCM), Dept. of Chemical Engineering, Madrid, Spain; Plant Research International (PRI), Wageningen, Netherlands; CERISS (Centro per l'Educazione, la Ricerca, l'Informazione su Scienza e Società), Milan, Italy; A\&F (Agrotechnology and Food Innovations) Wageningen, Netherlands; BP Chemicals, Hull, United Kingdom; Degussa AG, Hanau, Germany; DSM Research BV, Geleen, Netherlands; DuPont, Bad Homburg, Germany; NatureWorks, Naarden, Netherlands; Novozymes A/S, Bagsvaerd, Denmark; Roquette Freres, Lestrem, France; Shell International Chemicals BV, Amsterdam, Netherlands; Uniqema, Wilton/Redcar, United Kingdom. Final report. Available at http://www.chem.uu.nl/BREW/.

3. Steen, B. (1999). A Systematic Approach to Environmental Strategies in Product Development (EPS). Version 2000General System Characteristics. Centre for Environmental Assessment of Products and Material Systems. Chalmers University of Technology, Technical Environmental Planning. CPM report 1999:4.

4. PRé Consultants. (2004). SimaPro 6, Life Cycle Assessment Tool, Version Multi-user 6.0.1. Amersfoort, the Netherlands.

5. Nemecek, T., Heil, A., Huguenin, O., Meier, S., Erzinger, S., Blaser, S., Dux, D., \& Zimmermann, A. (2004). Life Cycle Inventories of Agricultural Production Systems. Final report ecoinvent 2000 No. 15. Agroscope FAL Reckenholz and FAT Taenikon, Swiss Centre for Life Cycle Inventories, Dübendorf, $\mathrm{CH}$, Available at www.ecoinvent.ch.

6. Brand, R., Pulles, T., van Gijlswijk, R., Fribourg-Blanc, B., \& Courbet, C. (2004). European Pollutant Emission Register (EPER). Available at http://www.eper.cec.eu.int.

7. International Energy Agency. (2002). Energy Balances of OECD (Organisation for Economic Co-operation and Development) Countries, 2000-2001.

8. Spielmann, M., Kägi, T., Stadler, P., Tietje, O. (2004). Life Cycle Inventories of Transport Services. Ecoinvent Report No. 14. Swiss Centre for Life Cycle Inventories, Dübendorf.

9. Doka, G. (2003). Life Cycle Inventories of Waste Treatment Services. Ecoinvent Report No. 13, Swiss Centre for Life Cycle Inventories, Dübendorf.

10. United Nations Environment Programme. (2001). Disasters. Cited at 20-01-2005. Available at http://www.unepie.org/ $\mathrm{pc} /$ apell/disasters/disasters.html.

11. Kleiber. (2004). Composition from Internet Addresses to Data Bases with Data Concerning Accident/Incidents. Cited at 20-01-2005. Available at http://www.umweltbundesamt. de/zema/eng/body_links.html.

12. European Environment Agency. (2001). Het milieu in Europa: de tweede balans. H13: Technologische ongevallen 
en natuurrampen. Cited at 20-01-2005. Available at http://reports. nl.eea.eu.int/92-828-3351-8/nl/13 nl.pdf.

13. European Communities. (2002). European Social Statistics, Accidents at Work and Work-Related Health Problems. Data 1994-2000.

14. European Communities. (2004). Work and Health in the EU. A statistical Portrait. Data 1994-2002.

15. European Agency for Safety and Health at Work. (2002). Newsletter. Cited at 24-12-2004. Available at http://agency. osha.eu.int/publications/newsletter/12/en/Newsletter12_EN. pdf.

16. Frischknecht, R., \& Faist Emmenegger, M. (2003). Strommix und stromnetz. In R. Dones (Ed.), Sachbilanzen von energiesystemen: Grundlagen für den ökologischen vergleich von energiesystemen und den einbezug von energiesystemen in ökobilanzen für die Schweiz. Final report Ecoinvent 2000 No. 6, Paul Scherrer institute Villigen, Swiss centre for life cycle inventories, Dübendorf, $\mathrm{CH}$.
17. Zah, R., \& Hischier, R. (2004). Life Cycle Inventories of Detergents. Ecoinvent. Report No. 12. Swiss Centre for Life Cycle Inventories, Dübendorf, 2004

18. Federal Statistical Office Germany. (2004). Life Expectancy in the New EU. Cited at 24-12-2004. Available at http://www.destatis.de/presse/englisch/pm2004/p2050022.htm.

19. North Yorkshire County Council. (2001). Employment by Industry. Cited at 15-11-2004. Available at http://www. northyorks.gov.uk/yourcouncil/NY\%20Employment \%20by\% 20Industry\%202001.pdf.

20. FAOSTAT data. (2004). Cited September 2004. Available at http://faostat.fao.org/faostat/collections?subset=agriculture.

21. University of Edinburgh (not dated): Cited at 24-12-2004. Available at http://www.safety.ed.ac.uk/training/presentations/ mh\%20why\%20are\%20you\%20here\%20slides/sld012.htm.

22. Unison. (2002). Unison News: Stress Leading to More Days Off. Cited at 24-12-2004. Available at http://www.unison.org. uk/safety/news'view.asp?did=542. 